\title{
NO MEIO DOS ESCOMBROS, A MEMÓRIA. $S H O A H$ E O TRAUMA NA QUEDA
}

\section{[In the Middle of the Rubbles, the Memory. Shoah and Trauma in the Fall]}

\author{
Jehnifer Penning ${ }^{1}$ \\ Helano Jader Cavalcante Ribeiro ${ }^{2}$
}

Resumo: A literatura e a história possuem muitas afinidades. Por ambas serem constituídas como narrativas, possuem a arte de contar histórias. Em vista disso, com esse trabalho, almeja-se em defender que é igualmente possível estudar e refletir acerca de algum fato histórico através do gênero literário como se fossem duas margens que se tocam e se mesclam. Assim, elenca-se como objeto de estudo o romance publicado em 2011, de autoria de Michel Laub, intitulado Diário da Queda. A obra em questão traz os conflitos dos personagens e sua relação com o trauma e a memória, em consequência das exposições ao choque vividos pelos personagens na Segunda Guerra. A proposta da pesquisa é refletir sobre esse período, cujas ruínas ainda pulsam no tempo-de-aqui-agora. Finalmente, tenciona-se responder a esses questionamentos no decorrer dessa pesquisa, sobretudo, com base nas teorias de Gagnebin (2009), Arendt (2012) e Adorno (1995). Conclui-se, através das discussões apresentadas, que existe a necessidade de discutir a Shoah no Brasil, uma vez que essa atrocidade aparece como mancha à história de todo ocidente e também porque no pós-guerra muitos imigrantes judeus vieram reconstituir suas vidas em território brasileiro, havendo, assim, a precisão de discutir seus passados e criar vínculos entre o ontem e o hoje.

Palavras-chave: Segunda Guerra; Literatura de Testemunho; Memória.

Abstract: Literature and history have many affinities. Because both are constituted as narratives, they have the art of storytelling. We would like, with this work, to defend that it is also possible to study and reflect on some historical fact through the literary genre as if they were two margins that touch and mix. Thus, we list as object of study the novel published in 2011, authored by Michel Laub, entitled Diary of the Fall. The work in question brings the conflicts of the characters and their relationship with trauma and memory, as a result of the exposures to the shock experienced by the characters in Second World War. Our proposal is to reflect on this period, whose ruins still pulsate in the time-of-here-now. Finally, we intend to answer these questions in the course of our research, mainly based on the theories of Gagnebin (2009), Arendt (2012) and Adorno (1995). It is concluded, through the discussions presented, that there is a need to discuss Shoah in Brazil, since this atrocity appears as a stain on the history of the whole West and also because in the postwar period many Jewish immigrants came to reconstitute their lives in Brazilian territory thus having the precision of discussing their past and creating links between yesterday and today.

Key-Words: Second World War; Literature of Testimony; Memory.

\footnotetext{
1 Doutoranda em Letras, área de concentração em Literatura, Cultura e Tradução na Universidade Federal de Pelotas. E-mail: j-penning@hotmail.com

2 Professor Adjunto no Curso de Bacharelado em Tradução na Universidade Federal da Paraíba (UFPB). E-mail: hjcribeiro@ gmail.com
} 


\section{CONSIDERAÇÕES INICIAIS}

O evento traumático que foi a Segunda Guerra Mundial aparece, recorrentemente, em obras de arte e na literatura. Ficções recontam e remontam a um passado não tão distante, que poderia ter sido verdade, com marcas que deveriam ser indeléveis. É sabido que a história e a literatura andam juntas, e, ainda que por muitos essa ligação não seja assimilada, podemos dizer que ambas constituem uma tênue relação, posto que se fundam na narrativa. Com base nisso, percebemos a possibilidade de refletir acerca de fatos e contextos históricos através da literatura como duas forças indissociáveis.

Dessa maneira, a justificativa para o trabalho advém de reflexões levantadas a partir da narrativa de Michel Laub, 2011, Diário da Queda. Na obra, o narrador-personagem lida com questões memorialísticas e traumáticas em decorrência da Segunda Guerra, sendo seu avô um imigrante ex-prisioneiro do campo de concentração de Auchwitz. O narrador, que não é nomeado, assim como a maioria das personagens, vivendo em uma realidade totalmente diferente - Brasil, Porto Alegre, anos 80, vida confortável e facilitada pelo poder aquisitivo de sua família -, não compreende a necessidade de pensar sobre a Shoah, de considerar a sua história.

Estudar a Segunda Guerra Mundial é, sem dúvida, ainda fundamental na contemporaneidade. Entretanto, quando um fato pertence a uma determinada comunidade, nação, isto é, à determinada coletividade e não a outra, o mesmo fato torna-se distinto para cada olhar. A proximidade cultural e cronológica de cada sucedido, ainda, transformam-no em algo dotado de sentido e valores ou distanciam-no da necessidade de trazê-lo à tona. Por conseguinte, estamos falando do Nazismo. Reconhecemos que em território brasileiro tal atrocidade certamente não será entendida como foi na Europa. No entanto, queremos defender que no Brasil também há a necessidade de rememoração.

A propósito, Jeanne Marie Gagnebin em Lembrar, escrever, esquecer (2009), especificamente no ensaio $O$ que significa elaborar o passado?, comenta sobre a facilidade que temos em deixar emudecido fatos da história. Segundo a filósofa, inclusive na própria Alemanha, as pessoas da geração pós-guerra insistiam em não falar no passado, em esquecer a Segunda Guerra Mundial. (GAGNEBIN, 2009) Se existia alguém que temia o esquecimento do Nazismo eram, sem dúvidas, os sobreviventes ao horror, posto que esses "não conseguiam esquecer-se nem que o desejassem". (Idem) Contudo, com a morte das testemunhas oculares da Shoah, compreendemos que vem aumentando o medo do esquecimento, uma vez que

meio século depois, a situação mudou. Dito brutalmente: conseguimos muito bem, se quisermos, esquecermo-nos de Auschwitz. Aliás, dadas a distância histórica e geográfica que separa o Brasil da Europa do pós-guerra, muitas pessoas entre nós nem precisam esquecer: simplesmente ignoram; ignoram, por exemplo, o que essa estranha palavra "Auschwitz" representa (GAGNEBIN, 2009, p. 99).

Pensando nesse sentido, trazemos os estudos Hannah Arendt (2012) e Walter Benjamin (2012), para falar de experiência enquanto conceito e compreensão, assim como reflexões acerca da memória e da necessidade de rememorar, o que contribui para a reflexão da 
importância de estudar a Segunda Guerra na contemporaneidade. Ilustrando a ideia de memória, lembremos de um romance, do português Gonçalo Tavares, intitulado Uma menina está perdida no seu século à procura do pai (2015), cujo trecho torna-se cabível citar:

ver bem ao longe, querido amigo, é uma das grandes qualidades da memória; não se trata só de ver para trás, mas também de ver ao fundo; a memória está mais ligada ao bom observador no espaço do que ao bom observador no tempo (TAVARES, 2015, p. 32).

Em síntese, o que tencionamos é encontrar um caminho para dúvida que permeia nosso questionamento inicial; responder se é necessário explorar tais assuntos, primeiro, em território brasileiro, e, segundo, em período cronológico distante do acontecimento, o que se torna a principal tarefa para essa pesquisa.

\section{RUÍNAS: A SHOAH, A LITERATURA E A MEMÓRIA}

Para atender nossa proposta de estudo, temos como objeto o livro Diário da Queda, publicado em 2011, de autoria de Michel Laub. O enredo é construído em formato de diário, que o narrador escreve por volta dos seus quarenta anos ao sentir necessidade de fazer um balanço de sua vida, a fim de resolver questões do passado. Desse modo, o que está em xeque no romance são conflitos acerca da memória e consequentemente do trauma.

Ainda que exista um início gráfico para a narrativa, esse não segue uma linha cronológica. Os fatos são colocados ao passo que vão sendo recordados pelo narrador, e mesmo que a escrita esteja acontecendo por volta de seus quarenta anos, o primeiro fato a ser registrado remonta aos treze anos daquele que nos conta a história. Em síntese, Diário da Queda (2011) é composto em fragmentos que não se assemelham em ordem cronológica.

Pensando na literatura atual, da qual tal romance faz parte, dizemos que essa está cercada de escritos que descentralizam o sujeito, buscam um discurso não muito preocupado com coesão e linearidade, e, sim, retratam o caos da sociedade em que se inserem esses narradores. Concordando com Jorge Fernando Barbosa do Amaral (2014), o qual também analisa a narrativa em questão, "o discurso fragmentado é, assim, o discurso do sujeito nômade, impessoal. Do sujeito caótico". (AMARAL, 2014, p. 84)

No entanto, em "Diário da Queda", essa fragmentação não está a serviço dessa desterritorialização do sujeito e nem tampouco da impessoalidade do narrador. $\mathrm{Na}$ verdade, a pessoalidade e as raízes dos personagens são alguns dos pontos cruciais do livro e o caráter fragmentado do livro é o reflexo da sinuosidade com que a memória do narrador se movimenta. Então, o texto configura-se não apenas como o veículo de transmissão da mensagem, mas sim ele mesmo como elemento produtor de significados (AMARAL, 2014, p. 84).

Assim, o que está em questão é o próprio modo de construção da narrativa, que põe em evidência a memória e o modo como ela aparece nas recordações do narrador. A escrita, 
dessa maneira, atua em conjunto com a memória. Como sabemos, o passado é recordado em parcelas e essas lembranças fragmentadas aparecem no livro, demarcando essa descontinuidade em representar esse mesmo passado.

A respeito do enredo, a história que retrata a personagem-narrador é a do avô, a do pai e consequentemente a sua, reconhecendo que todas elas estão intrinsecamente interligadas. $\mathrm{O}$ avô do narrador havia sido um imigrante europeu, judeu, ex-prisioneiro de campo de concentração. Nessa família, a questão judaica deve ser sempre lembrada, e as conversas giram em torno do Nazismo, do massacre e do sofrimento dos judeus; desse modo, não é permitido não reverenciar o passado dos descendentes do povo hebraico. O enredo, por conseguinte, é rodeado de conflitos entre gerações, espaço/tempo e religião.

A religião, a propósito, é vista de uma maneira bastante peculiar na narrativa. Começando pelo avô que, ao decidir não falar do seu passado, causa uma lacuna na história da família e sobretudo no quesito religião, uma vez que seu descendente, o pai do narrador, passa a carregar uma imagem totalmente depreciativa e negativa do judaísmo. Essa visão da religião judaica causa problemas na vida do pai, problemas ligados ao avô e às futuras gerações, posto que, como defende Lenida Kautz Menda: "na transgeracionalidade, as transmissões são inconscientes e poderão ser determinantes nas patologias das gerações seguintes". (MENDA, 2013, p. 23)

Meu avô não escreveu nada sobre judaísmo. Nenhum comentário sobre a conversão da minha avó. Nenhuma descrição das tentativas dela de entender a religião depois de se converter, os livros que ela leu, as idas dela à sinagoga sem que ele jamais a acompanhasse, as perguntas que ela fez sobre o tema sem que ele jamais desse mais que uma resposta lacônica. É possível que meu pai não tenha ouvido nenhuma frase dele a respeito quando criança, e muito poucas até completar catorze anos, uma explicação ou pista eventual sobre qualquer traço de identidade que o diferenciasse do mundo ao redor [grifo nosso] (LAUB, 2011, p. 30).

Como visto no fragmento acima, evidenciamos em primeira instância o fato de a religião não ser discutida na família. Pensando no judaísmo, dizemos que o caso da narrativa torna-se peculiar, reconhecendo que tal religião é historicamente carregada de tabus e preconceitos. No entanto, como o avô não passou nenhum ensinamento, nenhuma explicação da religião ao único filho, esse também não pôde sentir pela religião algo positivo. Para ele, ser judeu estava relacionado a algo muito negativo e preocupante; como o avô anulou o passado, o pai sentiu a necessidade de frisar a religião, ainda mais após o suicídio do avô.

Meu pai começou a se interessar por isso por causa da morte do meu avô, o que seria esperado numa circunstância assim, porque religião não é algo em que você pense aos catorze anos, mesmo que essa religião tenha a carga histórica e cultural do judaísmo, e mesmo que meu pai soubesse que a recusa do meu avô em tratar do tema desde sempre não tinha sido apenas um capricho, uma questão de gosto de um homem adulto que se interessa pelo que quiser, mas o sintoma de algo provavelmente visível na maneira de ele ser, de se mostrar diante da mulher e do filho e de todos [grifo nosso] (LAUB, 2011, p. 30-31). 
O personagem-pai da narrativa adota, em vista disso, uma conduta obsessiva em assuntos de sua religião. A explicação para tanto, nas palavras do narrador: "é tentador dizer que a reação do meu pai ao ler os cadernos influenciou a maneira como ele passou a tratar não só do judaísmo como de todas as outras coisas". (LAUB, 2011, p. 33) O narrador prossegue, dizendo que então, a partir da leitura dos cadernos3 foi que o pai começou a lidar com a memória do avô e com todos a sua volta, principalmente a própria família, de uma maneira em particular. O filho, o narrador da obra, por sua vez, não compreende o fanatismo do pai pela religião e pela memória.

Um fator determinante para o estudo da Segunda Guerra no Brasil é a grande leva de imigrantes europeus que vieram para o país em meados do século XX. Cooperando com essa ideia temos Ilana Heineberg (2011), que nos fala que o "Brasil recebeu uma onda migratória judaica importante no pós-guerra”. (HEINEBERG, 2011, p. 117) Como defende a teórica,

os sobreviventes do Nazismo, rapidamente neutralizados brasileiros, sentem, cerca de trinta anos depois de terem se instalado, uma vez que eles e suas próprias famílias estão bem estabelecidos, a necessidade e o dever de contar o inferno ao qual sobreviveram. A consciência da iminência da morte e o desaparecimento das últimas testemunhas oculares da Shoah, reforçam o "apelo da narrativa" (DULONG, 1991 apud HEINEBERG, 2011, p. 117).

Contudo, o narrador sente-se diferente de seu pai em tempo e espaço; e, relacionando-o ao avô, a distinção se acentua ainda mais.

Lembremos do fenômeno da globalização, o qual tem o papel, entre outros, de agregar um novo sentido ao local, articulando espaços e tempos, diminuindo, aparentemente, distâncias e realidades. Mas nem sempre. Na obra de Michel Laub, Diário da Queda (2011), a personagem do avô chega ao Brasil, enfrenta o novo e o passado ele opta por emudecer. O que reparamos na narrativa, desse modo, é uma lacuna entre o antes-agora, e, sem referências sobre o decorrido, o pai do narrador buscou, em todas as alternativas, histórias que contassem o que pudera ter sido a vida do avô.

Meu avô não gostava de falar do passado. O que não é de estranhar, ao menos em relação ao que interessa: o fato de ele ser judeu, de ter chegado ao Brasil num daqueles navios apinhados, o gado para quem a história parece ter acabado aos vinte anos, ou trinta, ou quarente, não importa, e resta apenas um tipo de lembrança que vem e volta e pode ser uma prisão ainda pior que aquela onde você esteve (LAUB, 2011, p. 8).

Verificamos no trecho citado o conflito existente entre lidar com o novo e também com o velho, ou seja, a tentativa de esquecer, nesse caso o passado, e aceitar um futuro, ten-

$3 \mathrm{O}$ avô deixou escritos dezesseis cadernos, onde contava sobre sua vida desde o dia em que chegara ao Brasil. No entanto, a escrita é extremamente surrealista, o que evidencia o trauma em relação ao passado e à própria religião. 
tando conciliar os dois mundos e realidades. Ter sido prisioneiro de Auschwitz impediu que o avô recomeçasse sua vida, embora estivesse desembarcado em um país novo, muito longe e totalmente distinto da Europa. "Nos cadernos do meu avô não há qualquer menção a essa viagem. [...] onde ele embarcou, se ele arrumou algum documento antes de sair, se tinha dinheiro...” (LAUB, 2011, p. 8)

Viu-se, assim, que o avô não conseguiu, ou provavelmente preferiu não, estabelecer um vínculo com a vida que teve na Alemanha, causando uma ruptura entre o seu país de origem e a pátria em que passou a viver no pós-guerra. Lembremos da pergunta que faz Anne Dufourmantelle (2003), quando, em um livro, convida Jacques Derrida para falar da Hospitalidade: "o que se torna um ser humano quando o despojam, não das coisas, nem mesmo da casa, mas do que o liga à interioridade?" (DUFOURMANTELLE, 2003, p. 116) Para muitas pessoas, a ruptura com suas raízes provoca um lapso muitas vezes irreparável na identidade.

Do ramo da família do meu avô morreram todos em Auschwitz, e não há uma linha a respeito deles nos cadernos. Não há uma linha sobre o campo em si, quanto tempo meu avô ficou lá, como fez pra sobreviver, o que sentiu quando foi libertado, e posso imaginar a reação do meu pai ao ler o texto, seis meses ou um ano depois da morte do meu avô, e perceber essa lacuna (LAUB, 2011, p. 30).

Não há dúvidas de que a vivência no campo de concentração deseja ser esquecida, ou mais, apagada da memória. Gagnebin (2009) retoma Nietzsche para falar que existe um esquecer natural sadio e necessário para que se possa sobreviver. Porém, há vezes que o passado, ainda que paralisado, assombra o presente. É o caso do avô de Diário da Queda. "O peso do passado era tão forte que não se podia mais viver no presente; esse peso era insuportável porque era feito não apenas (!) do sofrimento indizível das vítimas, mas também, e antes de tudo, da culpa [...]". (GAGNEBIN, 2009, p. 101)

Esse apagamento da história do avô fez diferença na vida das futuras gerações da família, como no caso do pai do narrador, por exemplo. O filho do avô, em busca de respostas, passou a imaginar como era a vida do seu pai sob o domínio de Hitler. Concordando com Berta Waldman, que escreve em seu estudo "Entre a lembrança e o esquecimento: a Shoá na literatura brasileira" (2015), dizemos que

se o avô não se refere a sua condição de imigrante e sua vitimização pelo nazismo, o pai o faz por ele, determinando o que não pode ser esquecido: o que uma maioria enlouquecidamente politizada é capaz de fazer com uma minoria, num esquema rígido de perpetrador e vítima (WALDMAN, 2015, p. 3).

Como lembrou Waldman (2015), não tendo respostas, o pai sentiu necessidade de conhecer o passado de sua família e buscou na literatura escrita pelos sobreviventes à Shoah.

Restou ao meu pai mergulhar naquilo que Primo Levi escreve a respeito: os homens que roubam a sopa uns dos outros em Auschwitz, os homens que mijam en- 
quanto correm porque não há permissão para ir ao banheiro durante o expediente em Auschwitz, os homens que dividem a cama com outros homens e dormem com o rosto nos pés desses outros homens e torcem para que eles não tenham pisado no chão por onde passam os que têm diarreia, e a capacidade de Primo Levi em dar dimensão ao que era acordar e se vestir e olhar para a neve no primeiro dia de um inverno de sete meses em que se trabalha em jornadas de quinze horas com água pelos joelhos carregando sacos de material químico ajudou meu pai a justificar os últimos anos de meu avô [grifo nosso] (LAUB, 2011, p. 80-81).

Porém, o pai haver recorrido às narrativas disponíveis a respeito do Holocausto ${ }^{4}$ para criar um passado para o avô, fez com que em nenhum momento se encontrasse a realidade. Uma porque eram estimativas, aproximações... poderia ter sido a vida do avô, mas nen huma fonte confirmaria. O pai, desse modo, acaba entrando em uma neurose, insistindo incessantemente no assunto de Segunda Guerra e justificando toda a sua existência a partir de discursos fanáticos.

Christian Ingo Lenz Dunker, em seu artigo Estrutura e personalidade da neurose: da metapsicologia do sintoma à narrativa do sofrimento (2014), faz um estudo a respeito da neurose. Dunker cita Henry Ey para explicar o que vem a ser neurose, e segundo ele podemos dizer que são "perturbações dos comportamentos, dos sentimentos ou das ideias que manifestam uma defesa contra a angústia e constituem relativamente a este conflito interno um compromisso". (EY, 1963, p. 145 apud DUNKER, 2014, p. 82)

O narrador explica sobre tal comportamento: "porque Auschwitz para ele nunca foi um lugar, um fato histórico ou uma discussão ética, e sim um conceito em que se acredita ou deixa de acreditar por nenhum outro motivo a não ser a própria vontade". (LAUB, 2011, p. 108)

Compreendemos que esse trauma que fora a Shoah, pode ser estendido não só aos familiares de ex-prisioneiros de campos de concentração, não só a judeus, como propôs Márcio Seligmann-Silva em seu ensaio A história como trauma (2000). É claro que a esses citados o assunto toca bem mais, por ser uma realidade mais tangível. Mas é válido pensar enquanto um marco de todo o ocidente. Como lembra Hannah Arendt (2012),

o antissemitismo (não apenas o ódio aos judeus), o imperialismo (não apenas a conquista) e o totalitarismo (não apenas a ditadura) - um após o outro, um mais brutalmente que o outro - demonstraram que a dignidade humana precisa de uma nova garantia, somente encontrável em novos princípios políticos e em uma nova lei na terra (ARENDT, 2012, p. 14).

Nas palavras da teórica, podemos visualizar que os feitos do Nazismo, mormente, são a mancha que se estende por todo o ocidente e não somente à Europa. "Nunca antes nosso futuro foi tão imprevisível”. (ARENDT, 2012, p. 11) Ignorar o passado, deixando que o sim-

4 Optamos por utilizar as duas palavras para referirmo-nos ao massacre nazista, isto é, utilizaremos tanto Shoah quanto Holocausto. Essa última, no entanto, será empregada quando o intuito for empregar uma carga mais negativa/destruidora ao contexto. 
ples correr do tempo acabe com as lembranças não é o ideal se o desejo é de compreender ou esperar por tempos melhores. Segundo Arendt:

já não podemos nos dar ao luxo de extrair aquilo que foi bom no passado e simplesmente chamá-lo de nossa herança, deixar de lado o mau e simplesmente considerá-lo um peso morto, que o tempo, por si mesmo, relegará ao esquecimento. A corrente subterrânea da história ocidental veio à luz e usurpou a dignidade de nossa tradição. Essa é a realidade em que vivemos. E é por isso que todos os esforços de escapar do horror do presente, refugiando-se na nostalgia por um passado ainda eventualmente intacto ou no antecipado oblívio de um futuro melhor, são vãos [grifo nosso] (ARENDT, 2012, p. 14).

A memória está intimamente ligada à noção de experiência. Entretanto, ainda conforme Arendt (2012), sabemos que não basta olhar para trás e lamentar as crueldades e tiranias, é preciso compreendê-las; e "compreender significa, em suma, encarar a realidade, espontânea e atentamente, e resistir a ela - qualquer que seja, venha a ser ou possa ter sido". (ARENDT, 2012, p. 21)

Caminhando para as considerações finais dessa análise inicial, podemos dizer que há a necessidade, sim, de pensar ainda na contemporaneidade as questões elencadas. Berta Waldman (2015) cita Theodor Adorno dizendo que é sutil o propósito da memória:

ele não afirma que devemos nos lembrar sempre de Auschwitz, mas fazer tudo para que algo semelhante não se repita. Não defende as comemorações e a homenagens, mas uma luta contra o esquecimento. Se essa luta é necessária, é porque não só a tendência de esquecer é forte, mas também o desejo de esquecer (WALDMAN, 2015, p. 5).

Desse modo, se esquecermos o que foi Auschwitz estaremos assumindo a nossa pobreza frente à experiência que não temos. Tal qual Silvio Ruiz Paradiso (2009), "uma das formas de estudar essa hecatombe, na qual foram mortos seis milhões de judeus, é através da literatura e da crítica literária”. (PARADISO, 2009, p. 2) Seguindo no raciocínio, dizemos:

de acordo com uma tese de Jan Assmann (1992), o passado só surge quando se pode remeter-se a ele, sendo assim uma criação cultural. Nesse sentido, tal criação é revelada através de um autor, e este fragmentado por inúmeras identidades que coincidem com sua situação étnica (judaica) de (re)criar uma memória uma terrível memória [grifo meu] (PARADISO, 2009, p. 1).

A literatura da Shoah tem grande importância para elucidar esse passado que muitas vezes insiste em sua mudez. Acrescentando-se a isso, e novamente concordando com Waldman, “um povo 'esquece' quando a geração que recebe o passado não o transmite à seguinte, ou quando essa geração recusa o que recebeu ou cessa de transmiti-lo". (WALDMAN, 2015, 
p. 7) Concebemos assim, duas formas de recuperar o passado: através da literatura e através dos ensinamentos que passam de geração em geração ${ }^{5}$.

Ao avô cabia o desejo recalcar suas memórias, posto que a realidade lhe fora cruel, inimaginável. Contudo, esse desligamento com o passado fez com que o trauma jamais fosse perscrutado. O pai, filho do avô, ao perceber esse lapso da memória, e ao perder o seu pai precocemente por conta de suicídio, julga por correto que a história de sua família jamais poderia deixar de ser subsumida da história do mundo.

A teórica Gagnebin (2009) também comenta sobre o trabalho de memória que vem sendo feito após certo distanciamento cronológico entre o hoje e a Segunda Guerra. A filósofa e escritora suíça reconhece que após a morte dos sobreviventes ao Nazismo, a preocupação em resgatar essa memória aumenta.

Nos dias de hoje, quando os raros sobreviventes dos campos de concentração nazistas morrem, um depois do outro, de morte dita natural ${ }^{6}$, a injunção à lembrança assume uma conotação bastante diferente do trabalho de memória tal como se desenvolveu no fim da Segunda Guerra Mundial (GAGNEBIN, 2009, p. 98-9).

Vendo na morte de tais sobreviventes o fim da testemunha para tais atrocidades, a busca pela memória do que não pode ser silenciado, cresce em grande escala. Com base nesse trabalho de memória, sabemos que "até hoje o nome 'Auschwitz', símbolo da Shoah, continua sendo o emblema daquilo que não pode, não deve ser esquecido". (GAGNEBIN, 2009, p. 98) Desse modo, Auschwitz "nos impõe um 'dever de memória'." (Idem) Em Gonçalo Tavares (2015), no já citado romance Uma menina está perdida no seu século à procura do pai, a tarefa da memória é "não deixar que se instale qualquer tipo de trégua ou suspensão, por, enfim, não desistirmos”. (TAVARES, 2015, p. 33)

Cooperando com a ideia anterior, também vemos o narrador de Tavares (2015) comparar a memória a uma corrida de resistência. Trata-se de um feliz cotejo, posto que muitas vezes perguntamo-nos: qual é a verdadeira tarefa da memória? No entanto, hesitamos em responder essa pergunta, talvez porque não exista uma única resposta que dê conta de explicá-la. Nas palavras da obra: "Não há qualquer objetivo numa corrida de resistência. (...) Isso é uma corrida de resistência. Trata-se de resistir - insistiu -, não há mais nada." (TAVARES, 2015, p. 107) A memória significa resistência.

Para concluir, trazemos novamente Diário da Queda (2011). Nas palavras do narrador: “em trinta anos será quase impossível achar um ex-prisioneiro de Auschwitz. Em sessenta anos será muito difícil achar um filho de ex-prisioneiro de Auschwitz”. E ele prossegue:

alguém lembra se morreram oitenta ou oitenta mil pessoas em Majdanek, duzentas ou duzentas mil pessoas em Sobibor, quinhentas mil em Belzec? Faz diferença

\footnotetext{
5 A história passada de geração em geração reflete o pensamento de Walter Benjamin acerca da experiência.

6 No excerto "de morte dita natural", reconhecemos certa ironia na fala da escritora, posto que se sabe que muitos dos sobreviventes cometeram suicídio ou desencadearam doenças decorrentes do grande trauma psíquico pós-guerra. Assim, reconhecemos que embora não tenham morrido nos campos de concentração, o Lager foi o que lhes matou.
} 
pensar em termos numéricos, no fato de que Auschwitz e os campos que seguiram o seu modelo mataram cerca de seis milhões de judeus? (LAUB, 2011, p. 118)

O narrador aponta ao fato de que até mesmo as mais cruéis desumanidades caem no esquecimento; e não será diferente com a Segunda Guerra, e, por consequência, com os campos de concentração. Assim, levanta-se a hipótese, na obra, que atrocidades, como o massacre dos judeus, podem voltar a acontecer. E isso revela o que está expresso claramente na narrativa, a inviabilidade da experiência humana em todos os tempos e lugares. (LAUB, 2011, p. 133) O trecho continua:

diante da qual não há o que fazer, o que pensar, nenhum desvio possível do caminho que meu avô seguiu naqueles anos, o mesmo período em que meu pai nasceu e cresceu e jamais poderia ter mudado essa certeza (LAUB, 2011, p. 133-134).

A falar das desumanidades, Márcio Seligamnn-Silva (2000) assume que "a Shoah é o superlativo por excelência da história. (...) tanto por causa da sua unicidade como também devido à impossibilidade de se reduzir esse evento ao mera mente discursivo". (SELIGMANNSILVA, 2000, p. 77). Entretanto, não defendemos que possamos atribuir ao Holocausto a ideia do superlativo. Concordamos, nesse sentido, com Gagnebin (2009), que fala na repetição dos fatos. Assim, não existem atrocidades idênticas, porém, elas são semelhantes. Cada terror presente na história é singular em sua essência.

A distinção entre idêntico e semelhante tem o mérito de ressaltar a singularidade dos acontecimentos históricos; a Shoah é singular sim e, nesse sentido restrito, única - mas não é o único acontecimento na longa cadeia de horrores, de aniquilações, de genocídios: há muitos outros acontecimentos diferentes, mas semelhantes no horror e na crueldade - a lista é lona e continua se alongando (...) (GAGNEBIN, 2009, p. 100).

Constatada a repetição na história, temos o fator que contribui ainda mais para o medo do pai do narrador de Diário da Queda, assim como também designa o próprio pensar do narrador: a incerteza. Não há nenhuma certeza que garanta o fim das guerras e dos genocídios e é essa inconstância que permeia não só as páginas do romance, mas também os dias da nossa existência. Portanto, não é preciso lembrar sempre do que passou; é preciso frisar, agora sim e sempre, que este passado pulsa no presente, uma espécie de agoridade cheia de história pronta para voltar.

\section{CONSIDERAÇÕES FINAIS}

Uma de nossas perguntas iniciais girava em torno da relevância de pensar a Segunda Guerra no Brasil, posto que não diz respeito a nosso passado imediato. Podemos responder que sim, é válido estudar o período nazista em território brasileiro. Como dito, com o grande número de imigrantes judeus vindos para o Brasil após a guerra, viu-se a necessidade 
de pensar suas origens a fim de estabelecer um vínculo com esse passado e relacioná-lo ao presente. Esses imigrantes, por sua vez, trouxeram também traços de sua cultura que, ao entrar em choque com o espaço encontrado, deram início a uma nova cultura, composta por traços do estrangeiro e agora do novo nacional.

Assim como fora difícil às futuras gerações do avô de Diário da Queda prosseguir sem saber do passado, assim também o é difícil para a contemporaneidade de forma geral justificar suas vivências se não se deter a questionar e refletir sobre a sua história. Pensar na memória ajuda na elaboração da própria consciência de identidade e pode ser uma forma de também impedir que atrocidades aconteçam novamente.

Lembrando ainda da globalização, sabemos que fatos não são mais encerrados ou isolados no local em que acontecem, pois, estão intrinsicamente relacionados ao global, e, assim, é como se todos os acontecimentos estivessem articulados. Destarte, é necessário ponderar todos os acontecimentos que precisam permanecer como aviso de incêndio, isto é, como alguma alerta para o que já aconteceu e pode acontecer de novo.

Sabemos que na narrativa, um dos medos constantes do pai do narrador é o esquecimento das atrocidades nazistas, e, assim ele cita demais guerras e demais acontecimentos, dizendo que ninguém mais os recorda, o que possivelmente também poderá acontecer com a Segunda Guerra Mundial.

Fica a questão: uma ética com base na memória é condição sine qua non para que haja possibilidade de experiência que não seja a do silenciamento e para que possamos trabalhar o trauma [ali, uma vez, deslocado, recalcado para o inconsciente]. Trauma esse no sentido maior, que se mostra, também, como trauma de toda a humanidade. Hannah Arendt (2012) nos mostra com receio que jamais em outrora vivemos tempos tão sombrios e inseguros, mas que a barbárie sempre retorna.

Citando Adorno (1995, p. 45), dizemos que não basta simplesmente remetermos ao passado, mas sim é preciso um esclarecimento, ou, como visto em Hannah Arendt, é preciso pensar em termos de compreensão. "No fundo, tudo dependerá do modo pelo qual o passado será referido no presente; se permanecemos no simples remorso ou se resistimos ao horror com base na força de compreender até mesmo o incompreensível”. (ADORNO, 1995, p. 45)

Nas obras literárias que recontam a história, encontramos o testemunho que possibilita uma visão ímpar e subjetiva do que encontramos escrito sob o senso comum. Dado que pensar na Segunda Guerra é uma tarefa necessária, visto que ainda lidamos com traumas desse Holocausto e que sabemos que a história sempre pode se repetir, ainda que de maneira diferente, defendemos que a partir da Literatura é possível encontrar um meio para refletir e elaborar estudos de caso, o que, assim, estará evocando a memória e pensando no presente o que não podemos deixar silenciado.

Finalmente, encerramos com base nas palavras de Jeanne Marie Gagnebin; pensando no passado tendo em vista uma compreensão/esclarecimento (memória) e elaborando o luto/melancolia que a ele está atrelado (trauma). Esse é "um trabalho que, certamente, lembra dos mortos, por piedade e fidelidade, mas também por amor e atenção aos vivos". (GAGNEBIN, 2009, p. 105) 


\section{REFERÊNCIAS BIBLIOGRÁFICAS}

ADORNO, Theodor. Educação e Emancipação. Rio de Janeiro: Editora Paz e Terra [recurso eletrônico], 1995.

AMARAL, Jorge Fernando Barbosa do. A memória conflituosa em "Diário da Queda". LING. - Est. e Pesq. Catalão-GO, vol. 18, n. 1, p. 79-88, jan./jun. 2014.

ARENDT, Hannah. Origens do Totalitarismo. São Paulo: Companhia das Letras, 2012.

BENJAMIN, Walter. Magia e técnica, arte e política: ensaios sobre literatura e história da cultura. (Obras Escolhidas v. 1) - 8ª ed. revista - São Paulo: Brasiliense, 2012.

DUFOURMANTELlE, Anne. Anne Dufourmantelle convida Jacques Derrida a falar Da Hospitalidade. / Jacques Derrida [Entrevistado]; Anne Dufourmantelle. - trad. de Antonio Romane. São Paulo: Escuta, 2003.

DUNKER, Christian Ingo Lenz. Estrutura e personalidade da neurose: a metapsicologia do sintoma à narrativa do sofrimento. Instituto de Psicologia da USP. São Paulo, v. 25, n. 1. p. 2014 ,96-77.

GAGNEBIN, Jeanne Marie. Lembrar, escrever, esquecer. São Paulo: Editora 34, 2009.

HEINEBERG, Ilana. Dois olhares sobre a Shoah na literatura brasileira: uma leitura dos contos "O Retrato", de Jacó Guinsburg, e "Na minha cabeça suja, o Holocausto", de Moacyr Scliar. WebMosaica. Revista do Instituto Cultural Judaico Marc Chagall. Porto Alegre/RS - vol. 3, n. 2, jul/dez, 2011.

LAUB, Michel. Diário da Queda. São Paulo: Companhia das Letras, 2011.

MENDA, Leniza Kautz. Diário da Queda: a força da transmissão entre gerações e a transgeracionalidade. WebMosaica. Revista do Instituto Cultural Judaico Marc Chagall. Porto Alegre/ RS - vol. 5, n. 2, p. 20-30, jul./dez., 2013.

PARADISO, Silvio Ruiz. Identidade pós-moderna judaica na literatura de Holocausto. Uma análise em Moacyr Scliar. In: VI ENCONTRO INTERNACIONAL DE PRODUÇÃO CIENTÍFICA CESUMAR, 2009, Paraná, Anais. Parará, VI EPCC, 2009.

SELIGMANN-SILVA, Márcio. A história como trauma. In: Catástrofe e representação: ensaios. - p. 7398 - Arthur Nestrovski, Márcio Seligmann-Silva (orgs.) - São Paulo: Escuta, 2000.

TAVARES, GONÇALO. Uma menina está perdida no seu século à procura do pai. São Paulo: Companhia das Letras, 2015.

WALDMAN, Berta. Entre a lembrança e o esquecimento: a Shoá na literatura brasileira. Arquivo Maaravi - Revista Digital de Estudos Judaicos da UFMG. Belo Horizonte/MG, v. 9, n. 17. 2015. 